\title{
Influence of Aspect Ratio on the Bearing Capacity and Correlated Modulus of Subgrade Reaction for Shallow Foundations on Dense Sand
}

\author{
Ramez Alchamaa \\ ramez.alchamaa@dorsch.com \\ Dorsch Gruppe, Doha, Qatar
}

\begin{abstract}
One of the most fundamental problems in the field of geotechnical engineering is the prediction of bearing capacity and settlement of shallow foundations on cohesion-less soil subjected to vertical central loading. The fact is that commonly used "SHAPE FACTORS" in the current design practice for estimating the bearing capacity and modulus of subgrade reaction of a shallow foundation are partially empirical values proposed by (Terzaghi, 1943). On the other hand, the current design of shallow foundation on cohesionless soil does not take into consideration the scale effect between the soil particles and foundation geometry. This may result in an excessively conservative design, which in turn results in unnecessary costs of the foundation. Therefore, and to take into account the realistic effect of the three-dimensional mechanism of soil deformation for foundations with various aspect ratios $\mathrm{B} / \mathrm{L}$ on the shape factor in the classical formulas and theories of ultimate bearing capacity of shallow foundation, a series of small-scale model foundation tests were carried out on a practical type of sand (Toyoura sand) and the three-dimensional mechanism of deformation has been closely monitored and recorded at the end of each performed test. This research presents the main observations and results of the square, rectangular and strip model tests with constant foundation base width B conducted on compacted sand. Finally, the results are presented and compared to those from literature and preliminary conclusions and recommendations are drawn.
\end{abstract}

Keywords: Model foundation test; Shape factors; Normalized foundation pressure

\section{INTRODUCTION}

The main objective of this paper is to investigate the bearing capacity of rough and rigid foundations with various shapes and aspect ratios placed on cohesion-less soil (sand) and correlate the modulus of subgrade reaction that is being commonly used for the flexible foundation design. To determine any differences in the behaviors of foundations with various shapes and aspect ratios and quantify these differences, the shape effect was investigated using model-scale square, rectangular and strip foundations with constant width B and various lengths for given homogenous sand properties. The observed behavior from model tests on dense (compacted) sand was presented and the obtained values of the normalized foundation pressure from the model tests results were compared with the commonly used values of bearing capacity factor $\mathrm{N} \gamma$ from traditional theories that consider the factor as a dimensionless factor and only related to the unit weight of soil $\gamma$ and its friction angle $\varphi$, where some recent studies by (De Beer, 1970) suggest that $\mathrm{N} \gamma$ factor appears to be a dependant factor on other parameters such as the aspect ratio $\mathrm{B} / \mathrm{L}$ of foundations, foundation width and some other soil properties. 


\section{MODEL SCALE FOUNDATION TESTS SET-UPAND USED APPARATUS}

To fulfill the main goals of this research, a new methodology for testing model-scale of foundations with various shapes was conducted and new mechanical apparatus' was developed in the soil mechanics laboratory at Tokyo Metropolitan University in the period between 2005 and 2007 (Alchamaa et al., 2005). The model foundation tests were all performed on uniformly fine-grained (Toyoura sand) in a test container; having internal dimensions of $60 \mathrm{~cm}$ in width, $180 \mathrm{~cm}$ in length and $60 \mathrm{~cm}$ in-depth and the lateral surfaces made of a transparent material namely (Acrylic-glass) with a thickness of $30 \mathrm{~mm}$. To eliminate any potential influence of the friction between the side acrylic walls and the tested sand within the test container on the model test results (especially the case of strip foundation), the sidewalls were well lubricated using a thin transparent film; smeared with a thin layer of waterproof grease; namely, silicone grease as shown in Figure 1.

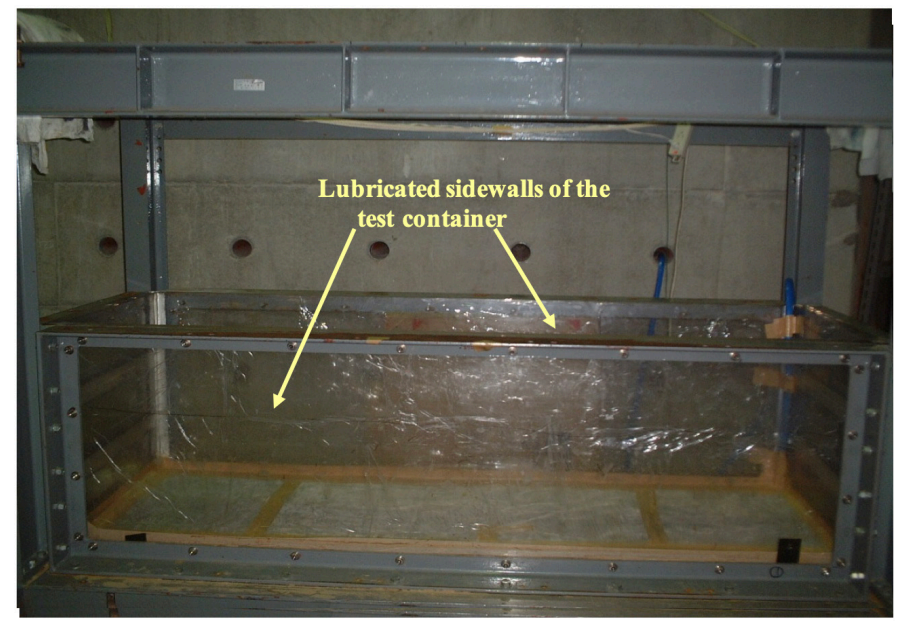

Figure 1: Lubricating the sidewalls of the test container before forming the sand bed

Moreover, the vertical loads were applied constantly to the foundation models using a loading frame connected to a manually controlled piston as it is shown in Figure 2, the relationship between load and displacement was measured and recorded digitally and saved on a computer utilizing the load and displacement transducers as illustrated in Figure 3.

It is worth to note that the width of foundation models remained constant $B=72 \mathrm{~mm}$ in all tests and the aspect ratios were $(L / B=1,1.5,2$ and $\infty)$ respectively in which the distance between the model foundation edge and the sidewalls is $12 B$ in the long direction of the test container. The foundation models were given a rough base and loaded at a constant rate of $0.5 \mathrm{~mm} /$ minute until a settlement of $0.5 \mathrm{~B}=36 \mathrm{~mm}$ occurred. Furthermore, the number of formed layers of sand in the test container in each test was about 20 layers on average. To form each layer, the sand was sifted and filtered during pouring into the test container layer by layer using standard test sieve (No. $0.85 \mathrm{~mm}$ ) to assure that the model foundations are placed on homogenous and uniformly fine-grained layers of sand in the test container. As a next step, each layer was completely prepared flat using some particular apparatus with a thickness of $18 \mathrm{~mm}$ and then compacted equally using 
a manual vibrator over a thin acrylic plate with no target of specific relative density as demonstrated in Figure 4. Besides, thin layers of black-dyed sand with a thickness of $(2 \mathrm{~mm})$ were created to allow a better observation of the vertical displacements at each layer.
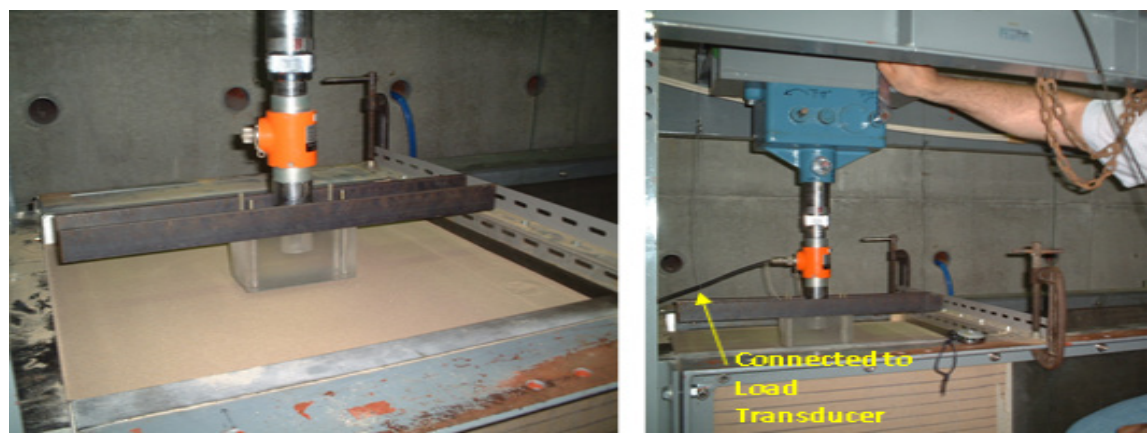

Figure 2: Loading frame and manually controlled piston used for applying vertical loads Constantly to model foundations
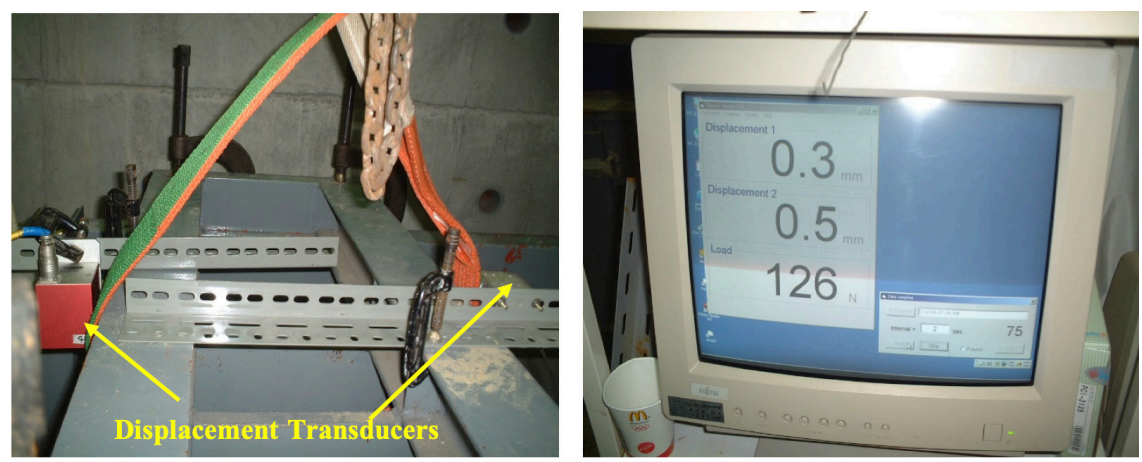

Figure 3: Installation of displacement transducers for measuring and recording the applied loads and resultant displacements

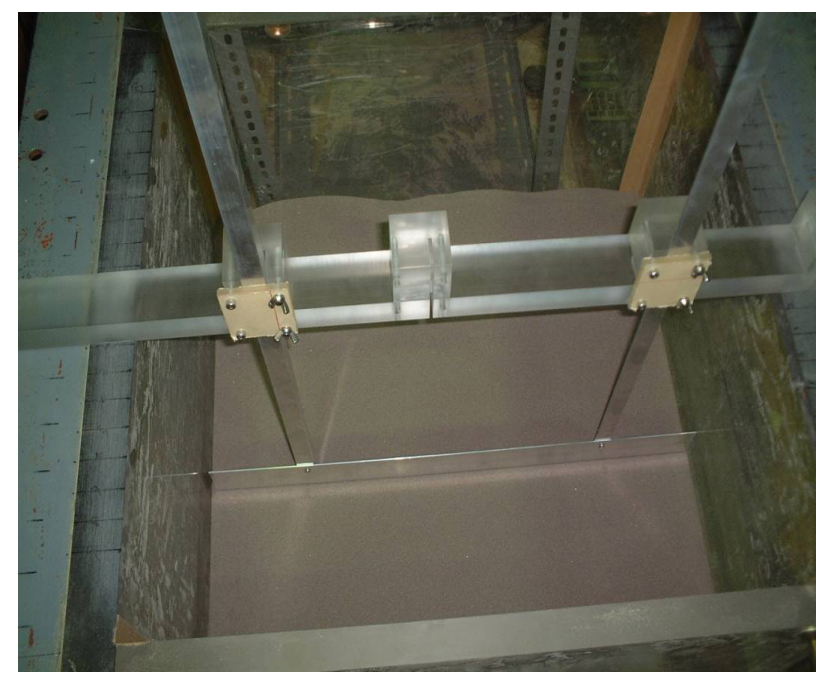

Figure 4: Manually-controlled instrument to form flat sand layers in the test container 


\section{RESULTS OF LOADING TESTS ON FOUNDATION MODELS, OBSERVATIONS AND DISCUSSION}

Theoretically, (Terzaghi, 1943) was the first one who suggested the general equation for determining the ultimate bearing capacity of a centrally loaded strip foundation on the surface of a uniform cohesion-less soil (without overburden soil stress effect) and that with zero cohesion can be simplified from three terms to one term to take the following form:

$$
q_{u l t}=\frac{1}{2} \gamma B N_{\gamma} S_{\gamma}
$$

where: $q_{u l t}=$ ultimate bearing capacity; $B=$ foundation width; $\gamma=$ unit weight of soil; $N_{\gamma}=$ bearing capacity factor; and $S_{\gamma}=$ foundation shape factor.

For small scale model foundation tests of known geometry, for which an assumed value of $\mathrm{S}_{\gamma}$ is used $\left(\mathrm{S}_{\gamma}=1\right.$ for strip foundations with $\left.\mathrm{L}=\infty\right)$ the only unknown in the previous equation is the bearing capacity factor $\mathrm{N}_{\gamma}$, which is considered in the literature by (Meyerhof, 1951) as a dimensionless factor and dependent on the friction angle $\varphi$ of the soil as stated previously. Moreover, for the series of model foundation tests carried out in this study, the peak point in foundation pressure - foundation penetration curves was simply defined and adopted for the back calculations of the normalized foundation pressure, $\mathrm{N}_{\gamma}$.

A summary of the testing conditions and results for each of these model tests is given in Table 1 while the loading test results are shown in Figure 5. The value of (the normalized bearing capacity factor) is used in order to compare all results from different model tests, where $\mathrm{N} \gamma_{\max }$ is equal to the $\mathrm{N} \gamma$ at the maximum value of $\left(2 \mathrm{q}_{\text {peak }} / \gamma \mathrm{B}\right)$ vs. the settlement (S) obtained from the model tests, where the maximum settlement $\mathrm{S}_{\max }$ was about $36 \mathrm{~mm}$ at the end of all tests as mentioned formerly.

Contrasting the proposed shape factors by (Terzaghi, 1943) that reveal that rectangular foundation capacity should take place between those of the square and strip foundations of the same width, the foundation pressure versus the foundation settlement curves for the series of model tests on sand have evidently demonstrated in Figure 5 that the rectangular foundation with aspect ratio $\mathrm{L} / \mathrm{B}=2$ has the highest bearing capacity. Additionally, the results in Table.1 indicate that the square and rectangular foundations with various aspect ratios, namely, $\mathrm{L} / \mathrm{B}=1,1.5$ and 2 have higher bearing capacities than strip foundation of the same width of about $19 \%, 26 \%$ and $61 \%$ respectively.

Table 1: Summary of model-scale foundation test results on compacted sand

\begin{tabular}{|c|c|c|c|c|c|}
\hline Foundation shape & $\begin{array}{c}\text { L/B ratio } \\
\text { for } \\
\text { constant } \\
\text { foundation } \\
\text { width } \\
\text { B= }=72 \mathrm{~mm}\end{array}$ & $\begin{array}{c}\text { Ultimate } \\
\text { bearing } \\
\text { capacity } \\
\text { qult }={ }_{\text {peak }} \\
(\mathbf{k P a})\end{array}$ & $\begin{array}{l}\text { Settlement } \\
\text { at } q_{\text {ult }}=\text { peak } \\
\text { (m) }\end{array}$ & $\begin{array}{c}\begin{array}{c}\text { Relative } \\
\text { settlement }\end{array} \\
\text { S/B (\%) } \\
\text { at } \text { qult }_{\text {peak }}\end{array}$ & $\begin{array}{c}\text { Observed failure condition } \\
\text { (Shear failure/ Maximum allowable } \\
\text { settlement) }\end{array}$ \\
\hline Square Foundation & 1.0 & 86 & 0.0033 & $4.6 \%$ & Punching shear failure \\
\hline Rectangular Foundation & 1.5 & 91 & 0.0045 & $6.2 \%$ & Local shear failure with deformed mass \\
\hline Rectangular Foundation & 2.0 & 116 & 0.0050 & $6.9 \%$ & Shear failure with extended deformation \\
\hline Strip Foundation & $\infty$ & 72 & 0.0038 & $5.3 \%$ & $\begin{array}{l}\text { Shear failure with many slip surfaces and } \\
\text { surface heave }\end{array}$ \\
\hline
\end{tabular}




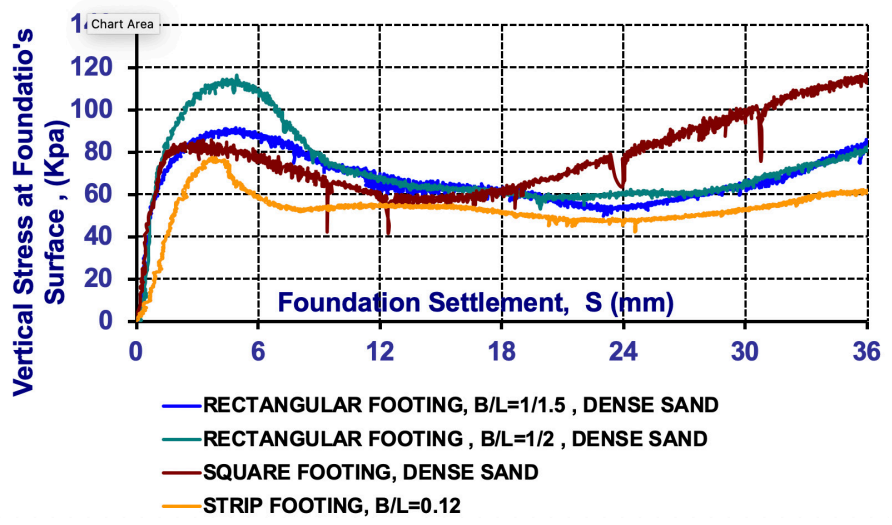

Figure 5: Vertical stress (pressure) at the foundations' surface vs. foundation settlement for model foundation tests on sand

The main observations and results from the model scale foundation tests on dense (compacted) sand are presented as following:

a) Square foundation, $(\mathrm{L} / \mathrm{B}=1)$ :

The major observations from square foundation is that the trace of deformation mechanism was extremely clear. Additionally, a minor heave surface is observed while the deformed mass of soil extends horizontally to a distance (less than $3 \mathrm{~B}$ ) and for about (B) in depth below the foundation; as shown in Figure 6(a).

b) Rectangular foundation, $(\mathrm{L} / \mathrm{B}=1.5)$ :

In this case, the slip surfaces were defined clearly which indicates that the resultant mode of failure (deformation) is about local shear failure. In addition, the slip surfaces extend horizontally up to (2.5 B) and for about (B) in depth below the foundation model, more to the point, a surface heave is observed as demonstrated in Figure 6(b).

c) Rectangular foundation, $(\mathrm{L} / \mathrm{B}=2)$ :

The main observations from this case is that the deformed mass of soil extends laterally to a distantance longer than (3B), while it extends in depth to a shallower distance in comparison to the previously presented cases for about (B). In addition, a significant surface heave is observed and many slip surfaces are defined below and around the foundation model surface; as shown in Figure 6(c).

d) Strip foundation, $(\mathrm{L} / \mathrm{B}=\infty)$ :

The most important observations from the case of strip foundation on dense (compacted) sand, where the plain strain condition was considered as a boundary condition of this model scale foundation test, can be presented as follows:

1. Numerous slip surfaces appeared within the passive wedge of the tested soil and the rigid soil wedge below the foundation as illustrated in Figure 6(d).

2. The observed slip surfaces extend horizontally to a length more than (4B) as shown in Figure 6(d). 


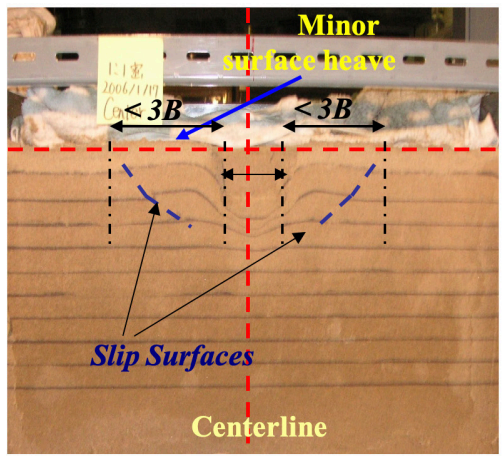

(a) Square foundation $(\mathrm{L} / \mathrm{B}=1)$

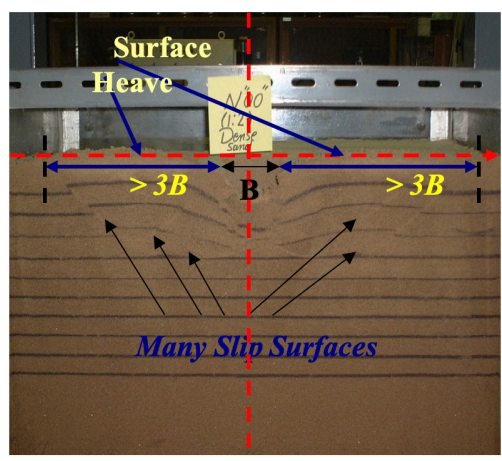

(c) Rectangular foundation $(\mathrm{L} / \mathrm{B}=2)$

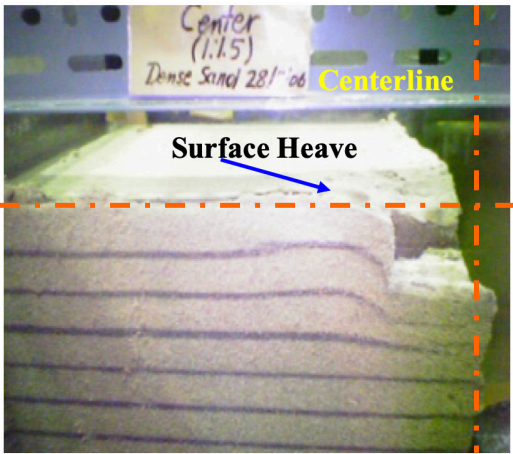

(b) Rectangular foundation ( $\mathrm{L} / \mathrm{B}=1.5)$

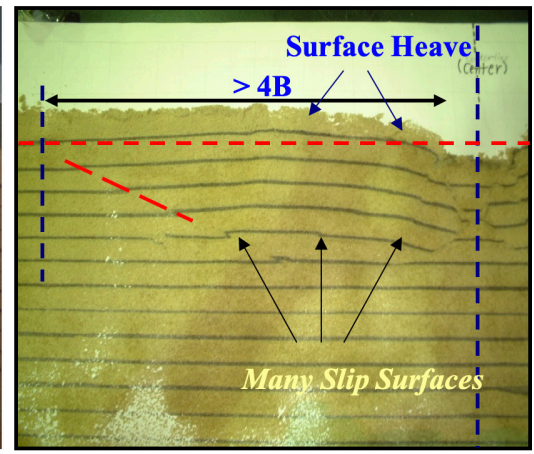

(d) Strip foundation $(\mathrm{L} / \mathrm{B}=\infty)$

Figure 6: Vertical cross-section at the center of the tested Toyoura sand for $(\mathrm{L} / \mathrm{B}=1,1.5$, 2 and $\infty$ )

However, the bearing capacity of a square foundation $(\mathrm{L} / \mathrm{B}=1)$ was remarkably larger than that purely under plain strain conditions for $(\mathrm{L} / \mathrm{B}=\infty)$. Furthermore, the observed shapes of triangle wedges (case of strip foundations) and the extension of the deformed volumes of soil from the performed cross-sections were different from those proposed by Terzaghi.

And as a matter of fact, (Terzaghi, 1943) did not consider the existence of the deformed volume of soil that extend widely and deeply around and beneath the foundation in $(3 \mathrm{D}$ sense) in his theory, which it seems somewhat reflects the influence of foundation shape (foundation behaviour) on the bearing capacity. This would suggest the introduction of new bearing capacity and shape factors that differ from those conservative ones proposed in the literature in addition to a potential correlation to the modulus of subgrade reaction that is widely used in the design of flexible foundations or the slab at grade type of foundation. Stating that the rigid foundation models in this paper are tested under central loads and remained plane when it settled, the modulus of subgrade reaction can be estimated for them by utilizing the soil reaction on the whole surface of the tested foundations as shown in Table 2. 
Table 2: Summary of base pressure, displacement, and modulus of subgrade reaction of model-scale foundations from literature and test results

\begin{tabular}{|c|c|c|c|c|c|c|}
\hline Foundation shape & $\begin{array}{c}\text { L/B ratio } \\
\text { for } \\
\text { constant } \\
\text { foundatio } \\
\text { n width } \\
B=72 \mathrm{~mm}\end{array}$ & $\begin{array}{c}\text { Ultimate } \\
\text { bearing } \\
\text { capacity } \\
\text { qult }_{\text {peak }} \\
(\mathbf{k P a})\end{array}$ & $\begin{array}{c}\text { Settlement } \\
\text { at } q_{\text {ult }}=\text { peak } \\
\text { (m) }\end{array}$ & $\begin{array}{c}\text { Ratio } \\
\left(\mathbf{q}_{\text {ult }}={ }_{\text {peak }} / \mathbf{S}\right) \\
\text { at } \mathbf{q}_{\text {ult }} \\
\left(\mathbf{k N} / \mathrm{m}^{2} / \mathrm{m}\right)\end{array}$ & $\begin{array}{c}\text { Modulus of } \\
\text { subgrade reaction } \\
\text { (Ks) by Bowles } \\
(1997) \\
\text { Ks }=40^{*} q_{\text {ult }} \\
\left(\mathbf{k N} / \mathbf{m}^{3}\right)\end{array}$ & $\begin{array}{c}\text { Governing } \\
\text { Failure } \\
\text { Criteria }\end{array}$ \\
\hline Square Foundation & 1.0 & 86 & 0.0033 & 26060 & 3440 & Shear failure \\
\hline Rectangular Foundation & 1.5 & 91 & 0.0045 & 20222 & 3640 & Shear failure \\
\hline Rectangular Foundation & 2.0 & 116 & 0.0050 & 23200 & 4640 & Shear failure \\
\hline Strip Foundation & $\infty$ & 72 & 0.0038 & 18947 & 2880 & Shear failure \\
\hline
\end{tabular}

Table 2 provides an attempt to conclude that the modulus of subgrade reaction is about the bearing capacity (pressure) per unit settlement that means soil capacity to withstand pressure for a given settlement in addition to a comparison between the estimated modulus of subgrade reaction based on the obtained test results on the foundation model tests and the presented equation in literature by (Bowles, 1997) for this purpose as follows:

$$
K s=40 q_{\text {ult }} \quad k N / m^{3}
$$

where: $\mathrm{q}_{\mathrm{ult}}$ is the ultimate bearing capacity for an assumed 1 inch or $25 \mathrm{~mm}$ settlement

However, it is obvious that there is a significant difference in the magnitude between the estimated values of the modulus of subgrade reaction for all foundation shapes in which the calculated values based on the previous equation are conservative and might have substantial cost implication on some construction projects as the equation has also limitations related to the governing failure criteria, so it cannot be applied to foundations where shear failure occurs before reaching the allowable settlement limit which is the reported case in this study as illustrated in Table 2.

\section{CONCLUSION AND RECOMMENDATIONS}

The following conclusions can be drawn from the results presented in this study:

- The mode of failure was found to be significantly influenced by the boundary conditions and the foundation shape.

- In contrast to what concluded in literature, that the foundation length does not influence the bearing capacity, 'the maximum pressure on square foundation on sand is equal to that on long strip of the same width' (Golder, 1941), the test results suggest that the square foundation has a higher capacity than the strip foundation of the same width with an evident impact of the foundation length and (L/B) ratio.

- The performed physical model tests conducted on compacted sand show obviously that the least ultimate capacity was obtained from strip foundation tests where the plain strain conditions are purely applied, whilst the square and rectangular foundations have higher capacities.

- In all model tests for foundations placed on compacted sand, the load-settlement curves reached their peak point at values of relative settlement $(\mathrm{S} / \mathrm{B})$ less than $10 \%$ in which the shear failure governs.

- It is also proved that observed trace on the soil top surface extends widely and deeply 
around the foundation edges proportionally with the increase in (L/B) ratios.

- Finally, it is always recommended that engineers should exercise caution before using such equations, also, the structural engineers should consult a geotechnical engineer proficient prior to finalizing soil stiffness and bearing capacity values and probably the selection of the best type and shape of shallow foundations to utilize the maximum capacity of the designed foundations.

\section{REFERENCES}

Alchamaa, R., Masaya, Y. \& Mitsutoshi, Y. (2005). Deformation and bearing capacity of foundations with various shapes under static loading. The proceeding of the $60^{\text {th }}$ JSCE Japan Society of Civil Engineers. (III-174, pp.495-496).

Bowles, Joseph E. (1997). Foundation analysis and design. (5th Edition), 1997.

De Beer, E.E. (1970). Experimental determination of the shape factors and the bearing capacity factors of sand. Géotechnique, 20(4), 387-411.

Golder, H.Q. (1941). The ultimate bearing pressure of rectangular footings. J. Int. Civil Engrs, 17:161-174.

Meyerhof, G.G. (1951) The Ultimate Bearing Capacity of Foundations. Geotechnique, 2, 301332.

Terzaghi, K. (1943). Theoretical Soil Mechanics. Wiley, New York. 